\title{
Human glycolipid transfer protein (GLTP) genes: organization, transcriptional status and evolution Xianqiong Zou ${ }^{\dagger 1}$, Taeowan Chung ${ }^{\dagger 2}$, Xin Lin ${ }^{1}$, Margarita L Malakhova ${ }^{1}$, Helen M Pike ${ }^{1}$ and Rhoderick E Brown*1
}

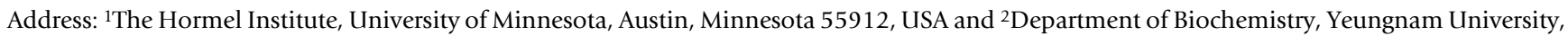
Kyeongsan 712-749, Republic of Korea

Email: Xianqiong Zou - xzou@hi.umn.edu; Taeowan Chung - twchung@yu.ac.kr; Xin Lin - xinlin12342004@yahoo.com; Margarita L Malakhova - margarita@hi.umn.edu; Helen M Pike - hmpike@hi.umn.edu; Rhoderick E Brown* - reb@umn.edu

* Corresponding author †Equal contributors
\end{abstract}

Published: 8 February 2008

BMC Genomics 2008, 9:72 doi:10.1186/147|-2164-9-72
Received: I October 2007

Accepted: 8 February 2008

This article is available from: http://www.biomedcentral.com/I47/-2/64/9/72

(c) 2008 Zou et al; licensee BioMed Central Ltd.

This is an Open Access article distributed under the terms of the Creative Commons Attribution License (http://creativecommons.org/licenses/by/2.0), which permits unrestricted use, distribution, and reproduction in any medium, provided the original work is properly cited.

\begin{abstract}
Background: Glycolipid transfer protein is the prototypical and founding member of the new GLTP superfamily distinguished by a novel conformational fold and glycolipid binding motif. The present investigation provides the first insights into the organization, transcriptional status, phylogenetic/evolutionary relationships of GLTP genes.

Results: In human cells, single-copy GLTP genes were found in chromosomes II and I2. The gene at locus IIpI5.I exhibited several features of a potentially active retrogene, including a highly homologous ( $94 \%$ ), full-length coding sequence containing all key amino acid residues involved in glycolipid liganding. To establish the transcriptional activity of each human GLTP gene, in silico EST evaluations, RT-PCR amplifications of GLTP transcript(s), and methylation analyses of regulator $C_{P G}$ islands were performed using various human cells. Active transcription was found for I2q24.II GLTP but IIpI5.I GLTP was transcriptionally silent. Heterologous expression and purification of the GLTP paralogs showed glycolipid intermembrane transfer activity only for 12q24.II GLTP. Phylogenetic/evolutionary analyses indicated that the 5-exon/4-intron organizational pattern and encoded sequence of I2q24.I I GLTP were highly conserved in therian mammals and other vertebrates. Orthologs of the intronless GLTP gene were observed in primates but not in rodentiates, carnivorates, cetartiodactylates, or didelphimorphiates, consistent with recent evolutionary development.
\end{abstract}

Conclusion: The results identify and characterize the gene responsible for GLTP expression in humans and provide the first evidence for the existence of a GLTP pseudogene, while demonstrating the rigorous approach needed to unequivocally distinguish transcriptionally-active retrogenes from silent pseudogenes. The results also rectify errors in the Ensembl database regarding the organizational structure of the actively transcribed GLTP gene in Pan troglodytes and establish the intronless GLTP as a primate-specific, processed pseudogene marker. A solid foundation has been established for future identification of hereditary defects in human GLTP genes. 


\section{Background}

Glycosphingolipids (GSLs) and related metabolites are found ubiquitously in eukaryotes and mediate key functions involving cell membranes, including immune responses, drug resistance, surface adhesion, neuroregeneration, differentiation, and apoptosis [1-6]. Glycolipid transfer protein (GLTP) is a soluble protein (209 amino acids; $24 \mathrm{kDa}$ ) that can selectively transfer GSLs between membranes [7-13]. GLTP has been implicated in the Golgi-to-plasma membrane, nonvesicular trafficking of glucosylceramide, a key intermediate in the synthesis of higher GSLs and in cellular drug resistance $[11,14,15]$. In order to bind glycolipid, GLTP utilizes an all $\alpha$-helix conformation, arranged in a two-layer 'sandwich motif' containing no intramolecular disulfides, to form a single glycolipid liganding site [16-18]. Comparative structural analyses of GLTP in various GSL-free and GSL-complexed forms, along with crystallographic B-factor distributions, suggest that a cleft-like gating mechanism, involving conformational changes to two interhelical loops and one $\alpha$ helix, facilitates entry and exit of the lipid chains in the membrane-associated state. Acquisition of glycolipid occurs via an adaptive recognition process involving a sugar headgroup recognition center that forms multiple hydrogen bonds and van der Waals contacts to selectively anchor the sugar-amide moieties to amino acid side chains of the protein surface as well as a 'molded-to-fit', hydrophobic tunnel to accommodate the hydrocarbon chains of the ceramide moiety [13,16-18].

The novel architecture of GLTP markedly contrasts the conformational motifs of other lipid binding and transfer proteins which generally are dominated by $\beta$-sheet, i.e. $\beta$ grooves/concave cups and $\beta$-barrels, or helical bundles stabilized by multiple disulfide-bridges, i.e. saposin-folds. Such proteins include sphingolipid activator proteins, CD1 proteins, ceramide transfer protein, phosphoglyceride transfer proteins, other START-related proteins, nonspecific lipid transfer proteins, fatty acid binding proteins, lipocalins, and plant lipid transfer proteins $[13,16,17]$. GLTP also forms a membrane targeting motif that differs from those used by other important peripheral proteins, i.e., $\mathrm{C} 1, \mathrm{C} 2$, PH, FYVE, and PX domains. The unique structural aspects of the glycolipid binding pocket and the membrane interaction region of GLTP establish the GLTPfold as the prototype of the GLTP superfamily [19-22]. GLTP domains recently have been identified in other proteins, such as the ubiquitously-expressed phosphatidylinositol 4-phosphate (PtdIns(4)P) adaptor protein-2 (FAPP2) which is involved in vesicular trafficking from the Golgi to the cell surface and glucosylceramide transfer during GSL synthesis $[23,24]$. Other GLTP orthologs have been linked to the programmed cell response induced by stress in plants (e.g. ACD11) [25] and as part of the selfnonself recognition and compatibility response during heterokaryon fusion in filamentous fungi (e.g. HET-C2) $[13,26]$.

The present study provides the first characterization of genes encoding GLTP. In humans, single-copy GLTP genes were located to chromosomes 11 and 12, encoding highly homologous GLTPs ( 94\%). The GLTP gene at locus $11 \mathrm{p} 15.1$ exhibited several characteristic features of a potentially active retrogene, affording the opportunity to critically evaluate RT-PCR limitations for accurate determination of single-copy, pseudogene expression. Assessment of transcriptional activity by RT-PCR required extensive controls to ensure accurate conclusions and was aided by determination of the methylation status of $5^{\prime}$ UTR CpG islands as well as by comparative phylogenetic/ evolutionary analyses of human GLTP genes with other vertebrate GLTP genes. The organizational pattern of the transcribed human GLTP gene (5-exon/4-intron and exon sizes) and the encoded GLTP amino acid sequence were highly conserved among various therian mammals and other vertebrates. In contrast, orthologs of the human intronless GLTP gene were found only in primates (Pan, Macaca) and were not present in rodentia (Mus, Rattus) carnivora (Canis), cetartiodactyla (Sus, Bos), or didelphimorphia (Didelphis), consistent with recent evolutionary development as a primate-specific, processed pseudogene.

\section{Results \\ Organization of Human GLTP Genes}

To identify the human gene(s) encoding GLTP, the sequences of cDNAs that we previously cloned from GLTP mRNA of human skin fibroblasts and glioma cells (GenBank AF209074, AY372530, AY372531, AY372532) were used in BLAST searches of the NCBI Human Genome. Highly homologous genomic DNA sequences were found at loci on two different chromosomes: $12 \mathrm{q} 24.11$ of chromosome 12 ( $>99 \%$ identity) and 11p15.1 of chromosome 11 ( $94 \%$ identity). Five separate sequences, interspersed at the 12q24.11 locus, were identical with five segments comprising the full-length GLTP cDNA ORF (630 bases), suggesting the presence of a GLTP gene with five exons separated by four introns (Figure 1). When adjoined in 5'-to-3' fashion, the five exons encoded the same 209 amino acid sequence that we previously determined for human GLTP by RT-PCR using purified mRNA $[16,27]$. The first intron was substantially larger $(21,530$ bases) than the other three introns $(1,023,1,756$, and 2,881 bases). All exon/intron boundaries were characterized by classic consensus nucleotide sequences expected for splice sites, i.e. introns contained $5^{\prime}$ GT and 3' AG dinucleotides as well as upstream pyrimidine tracts [28]. The 5'-3' arrangement of the five exons, the presence of classic intron dinucleotide sequences at all exon/intron junctions, and the $100 \%$ homology of the five exons at the 12q24.11 locus with the full-length ORF in GLTP mRNA 


\section{GLTP (locus 12q24.11)}

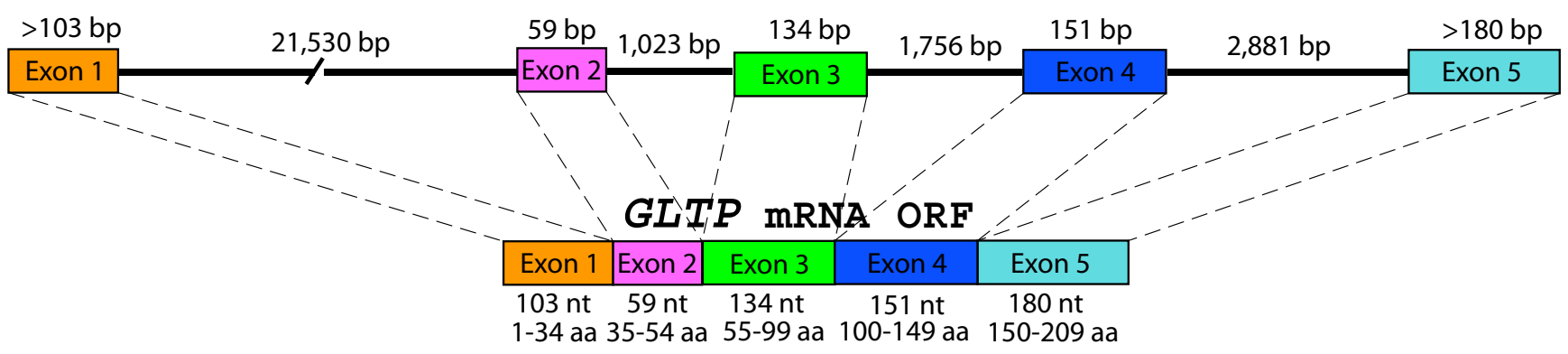

\section{intronless GLTP (locus $11 \mathrm{p} 15.1$ )}

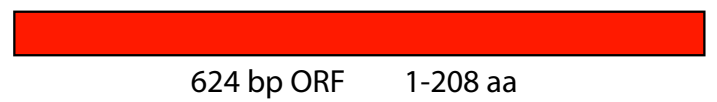

Figure I

Organization of Human GLTP Genes.

were consistent with transcript maturation by cis splicing processes [28].

Alignment of the human cDNA ORFs (630 bases) encoding GLTP (AF209074, AY372530, AY372531, AY372532) also revealed $\sim 94 \%$ homology with a single genomic DNA sequence at locus $11 \mathrm{p} 15.1$ in chromosome 11 (Figure $2 \mathrm{~A}$ ). The genomic sequence ( 627 bases) contained both start (ATG) and stop (TAA) codons and encoded a near full-length GLTP-like protein (208 a.a.) lacking only Lys146 (Figure 2A). Absent from the GLTP-like sequence was AGA from within the $\mathrm{CAG}^{435}$ AAGATC TTC $^{444}$ region, affecting two potential codons (Figure 2A; cyan highlight). Fortuitously, the deleterious effect of the missing AGA was minimized and resulted only in the loss of a single lysine residue. The remaining $\mathrm{CAG}^{435} \mathrm{ATC} \mathrm{TTC}^{441}$ sequence kept the reading frame fidelity in tact without alteration of subsequent codons. Altogether, nucleotide deletions and substitutions delineated a total of 13 different amino acids in the GLTP paralog, resulting in 94\% identity with GLTP encoded at locus 12q24.11 (Figure 2B).

Comparison of the encoded sequences for human GLTP and the GLTP paralog (Figure $2 \mathrm{~B}$ ) revealed the presence of all residues previously shown to be important components of the glycolipid liganding site, encompassing both the glycolipid recognition center (Asp48, Asn52, Lys55, Trp96, His140, Tyr207, Val209) and the hydrophobic tunnel (Leu4, Leu30, Phe33, Phe34, Leu37, Val41, Phe42, Pro44, Ile45, Ile49, Phe103, Ile104, Phe107, Leu108, Ala128, Leu136, His140, Val144, Ile147, Ala151, Leu152, Ala155, Phe161, Leu165) [16,29]. The 94\% overall homology of the GLTP paralog for human GLTP was similar to that of mouse GLTP and was much greater than that of HET-C2 fungal GLTP ortholog, which actively transfer glycolipids [26]. Thus, the evidence suggested that the intronless GLTP gene (GLTPi) at locus 11p15.1 might be a retrogene with the potential to express active protein.

\section{Transcriptional Status of Human GLTP Genes}

To determine whether the NCBI human expressed sequence tag (EST) database contained any evidence for mRNA transcript of the 11p15.1 GLTP paralog, BLAST searches were performed against both the GLTPi ORF at 11p15.1 and the 5-exon/4-intron GLTP ORF at 12q24.11. More than 100 sequences matched positively to human 5exon/4-intron GLTP ORF, indicating active transcription for the GLTP gene at locus $12 \mathrm{q} 24.11$ in a variety of cells. However, one EST clone (CF619013) derived from pooled chondrosarcoma tumor cells matched identically with the GLTPi ORF at locus 11p15.1, with its nearly fulllength ORF (627/630 bases) including start (ATG) and stop (TAA) codons. Thus, the possibility remained that GLTPi at 11p15.1 could be an active retrogene, expressed only at certain times during cell development or only in select cell types [30]. To directly assess the transcriptional status of both GLTP genes in vivo, RT-PCR analyses were performed on the total RNA isolates from various human cells. To circumvent the difficult task of identifying primers and PCR cycling conditions that could reliably and unequivocally discriminate between the highly homologous ORFs predicted from the two GLTP genes, PCR reactions were performed with 'GLTP universal primers' designed to amplify equally well either 562 or 559 base sequences of either GLTP ORF (Figure 2A). This strategy 


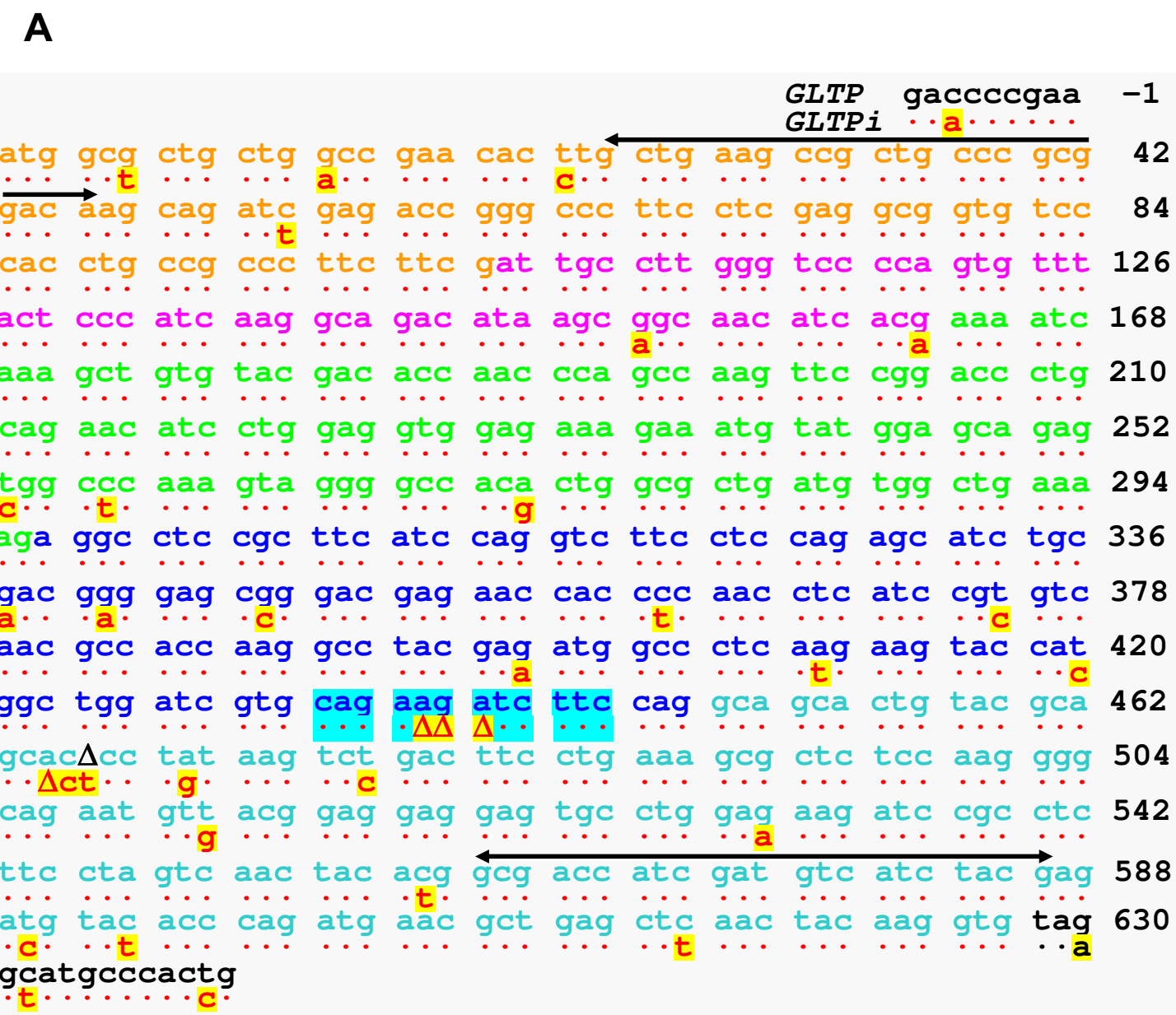

B

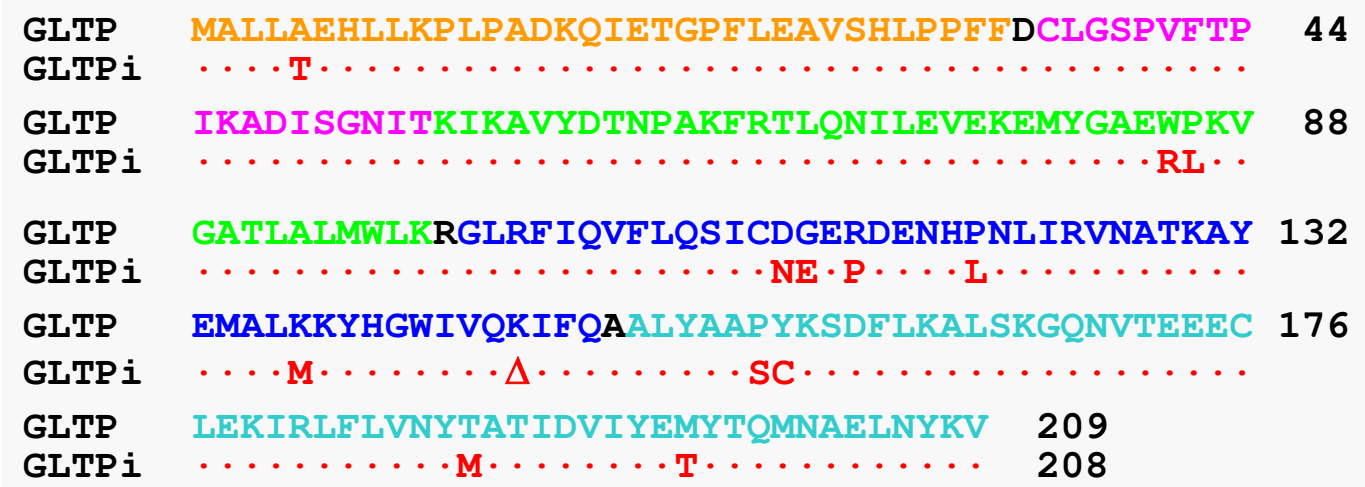

Figure 2

Sequences of Human GLTP Genes and Predicted Translation Products. A. Nucleotide ORF Sequences of 5-exon/4intron GLTP and intronless GLTP (GLTPi). The black horizontal lines show the locations of the GLTP 'universal primers' used for PCR analyses. B. Encoded Amino Acid Sequences of Human GLTP Homologs. Different sequence coloring distinguishes the exon source of 5-exon/4-intron GLTP. 
had the benefit of providing a PCR response expected to directly correlate with the relative abundance of the two potential GLTP transcripts, irrespective of chromosomal origin. Careful optimization of PCR cycling conditions avoided caveats associated with high cycling PCR, which can amplify the slightest traces of genomic DNA present in RNA isolates and lead to erroneous conclusions. Controls using only Platinum Taq DNA polymerase without reverse transcriptase (No-RT controls; see Additional file 1, Figure S1) established the critical number of PCR cycles in our experiments to be 35-37 to maximize detection of potential GLTP transcripts from the single-copy genes while avoiding spurious contributions from amplified genomic DNA of GLTPi remaining in the DNase-treated transcript isolates.

Figure 3A shows the results obtained using an optimized number of PCR thermal cycles (37 cycles) with DNasetreated RNA isolates from glioma cells (lane 1), human skin fibroblasts (lane 3), HBL100 breast cancer (lane 5), T47D breast cancer (lane 9), breast cancer HTB-126 (lane 13), Gaucher cells (lane 7), Caov3 ovarian cancer (lane 15), IMR-32 neuroblastoma (lane 11). No-RT PCR controls are shown in even numbered lanes (Figure $3 \mathrm{~A}$ ).
Cloning of PCR products using pGEM-T vector and restriction analysis using BspHI enabled efficient and rapid determination of RT-PCR product source (e.g., 5-exon/4intron GLTP or GLTPi). Figure 3B shows the control BspHI restriction pattern obtained by digestion of $\mathrm{pGEM}-\mathrm{T}$ vector with the different GLTP ORF inserts (corresponding pGEM-T vector map and BspHI sites, see Additional file 1, Figure S1A). Analyses of more than 120 clones from different cell lines (Figure 3A) using optimized PCR conditions produced restriction patterns consistent only with the 5-exon/4-intron GLTP gene being the source of transcribed mRNA (see Additional file 1, Figure S1C). Sequencing of representative clones verified the restriction digest patterns. Only when the number of RT-PCR cycles exceeded 40 were clones occasionally found displaying the GLTPi cDNA restriction pattern (see Additional file 1, Figure S1B). Even so, No-RT PCR controls were consistent with the GLTPi cDNA being derived from trace contamination by GLTPi genomic DNA. Thus, active transcription involved only the single-copy, 5-exon/4-intron GLTP gene, with transcript levels being relatively high in human glioma cells and Gaucher cells. Although expression levels in human skin fibroblasts were relatively low and difficult to visualize in agarose gels (Figure $3 \mathrm{~A}$, lane 3 ), the pres-

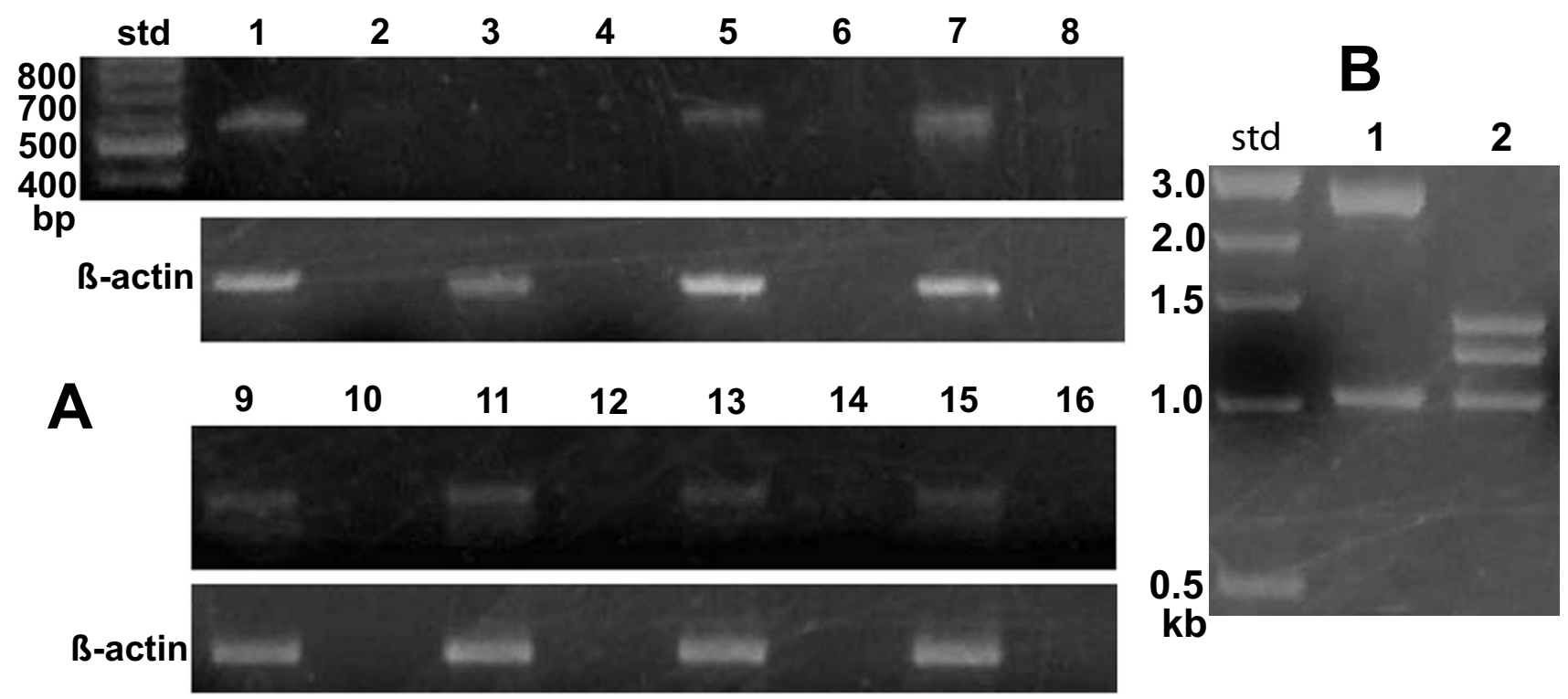

\section{Figure 3}

Transcriptional Status of Human GLTP Genes. A. Agarose gel electrophoresis patterns of PCR products (37 cycles) obtained with 'universal GLTP primers' from different cells. Odd numbered lanes = RT-PCR; Even numbered lanes = No-RT PCR controls (PCR with no reverse transcriptase); Lanes I \& 2 = glioma cells; Lanes 3 \& 4 = human skin fibroblasts; Lanes 5 \& $6=$ human HBLI00 breast cancer cells; Lanes $7 \& 8=$ Gaucher cells; Lanes 9 \& $10=$ human T47D breast cancer cells; Lanes II \& I $=$ human IMR32 neuroblastoma cells; Lanes I3 \& I4 = human HTBI26 breast cancer cells; Lanes I5 \& $16=$ human Caov3 ovarian cancer cells. $\beta$-actin transcription is shown in subtending panel at 30 PCR cycles. B. Agarose gel electrophoresis patterns obtained after $\mathrm{BspHI}$ restriction digestion of $\mathrm{pGEM-T}$ clones containing GLTP ORFs originating from 5-exon/4-intron GLTP (Lane I) or from intronless GLTP (Lane 2). Std = molecular weight standards. 
ence of 5-exon/4-intron GLTP PCR product was confirmed by excision and cloning of the corresponding gel region. Transcription of GLTPi was not evident in any of the analyzed cells by the preceding criteria.

Methylation Status of CpG Islands in Human GLTP Genes CpG dinucleotides in the 5 ' end regions of transcriptionally active chromosomal alleles generally are unmethylated. Conversely, methylation of CpG islands is a known indicator of transcriptional silencing [31-33]. In human GLTPi, a 255 base sequence including the 5' UTR (-128 bases) and initial portion (20\%) of the potential ORF (see additional file 1, Figure S2), met the criteria of a CpG island [31-34]. To assess methylation status, human blood genomic DNA was treated with bisulfite to convert unmethylated cytosines to uracils while leaving any methylated cytosines unaltered. Primers containing no $\mathrm{CpG}$ dinucleotides were used for PCR to avoid bias between DNA templates based on their original methylation status [34,35]. The results obtained by sequencing, after clonal amplification using pGEM-T, are shown in Figure 4. The $23 \mathrm{CpG}$ dinucleotides, localized in the $\mathrm{CpG}$ island of GLTPi, were highly methylated in all clones (Figure 4A, filled circles), consistent with transcriptional silencing.

In the 5-exon/4-intron GLTP gene, the CpG island (666 bases) included a larger 5' UTR region ( -476 bases) along with all of the Exon 1 ORF (103 bases) and the initial 87 bases of Intron 1 (see Additional file 1, Figure S2). Consistent with designation as a CpG island was the very high
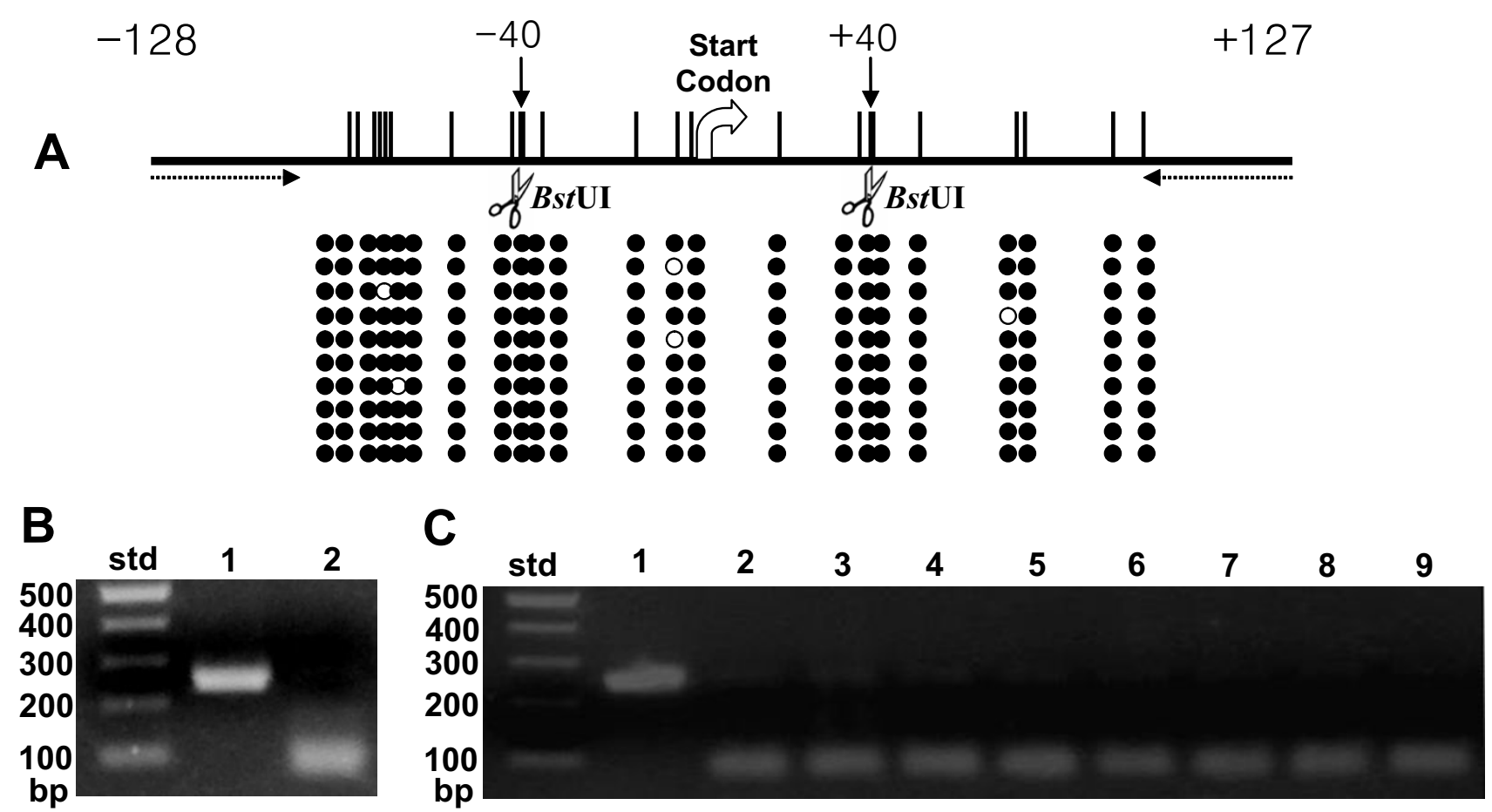

Figure 4

Methylation Status of Human Intronless GLTP Gene. Vertical bars show location of CpG dinucleotides. BstUI restriction sites, consisting of adjacent CpG dinucleotides, are shown by scissors. Individual clones are shown by horizontal rows of circles. Filled circles represent methylated CPG dinucleotides; unfilled circles represent nonmethylated CpG dinucleotides. Primers for RT-PCR ( 255 base product) are indicated by dotted arrows. The ATG start codon represents nucleotides $+1,+2$, and +3. B. \& C. Combined bisulfite restriction analysis (COBRA) of intronless GLTP gene methylation status. B. Agarose gel electrophoresis patterns obtained before (Lane I) and after (Lane 2) BstUI restriction digestion of bisulfite-treated PCR products for intronless GLTP gene (GLTPi) in human blood cell genomic DNA. C. COBRA analysis of intronless GLTP methylation status in different cell types. Lane I = pooled PCR products before BstUl restriction digestion; Lanes 2-9 shows action of BstUI restriction digestion. Lane 2 = glioma cells; Lane 3 = human skin fibroblasts; Lane 4 = human HBLI00 breast cancer cells; Lane 5 = Gaucher cells; Lane $6=$ human T47D breast cancer cells; Lane $7=$ human IMR32 neuroblastoma cells; Lane $8=$ human HTBI 26 breast cancer cells; Lane $9=$ human Caov3 ovarian cancer cells. Because of the absence of BstUl restriction sites in amplified PCR products of the CPG island of the 5-exon/4-intron region, COBRA analysis could be used to verify the absence of methylation detected by direct sequencing and served only as a negative control for BstUl action shown Panel C. Std = molecular weight standards. 
G-C content ( $76 \%$ overall), that reached $80 \%$ and $84 \%$ in the 5'UTR regions -450 and -300 from the translation initiation site, respectively. The very high concentration of CpG dinucleotides (88 sites) in the CpG island severely limited the locations where 'CpG-free' primers, having the required 20-30 base sequence length, could be used to obtain the desired PCR products ( $<300$ base long) $[34,35]$. The criteria were met by a 201 base sequence containing 11 CpG sites in the 5'UTR (-559 to -359) of the 5exon/4-intron GLTP gene. Bisulfite treatment followed by sequencing of clones showed all $11 \mathrm{CpG}$ sites to be completely unmethylated (see Additional file 1, Figure S2), consistent with active transcription of the 5-exon/4-intron GLTP gene.

To confirm the sequencing data for human blood cell genomic DNA and further analyze the methylation status of the CpG island of GLTPi in various other human cells, combined bisulfite-restriction analysis (COBRA) was performed (35). Figures $4 \mathrm{~B}$ and $4 \mathrm{C}$ show the COBRA data obtained for the GLTPi CpG island. Figure 4B shows the PCR products after bisulfite treatment of human blood cell genomic DNA before (lane 1) and after (lane 2) Bst UI restriction digestion, which cuts only when two adjoining CpG dinucleotides within the recognition site are methylated (lane 2). Figure 4C shows results obtained with glioma (lane 2), skin fibroblasts (lane 3), breast cancer [HBL100 (lane 4), T47D (lane 6), and HTB-126 (lane 8)], Caov3 ovarian cancer (lane 9), IMR-32 neuroblastoma (lane 7) and Gaucher cells (lane 5). Although traces of undigested amplified products were detected (Figure 4C, lanes 2-9), nearly all amplified PCR products from GLTPi CpG islands were cut by BstUI, consistent with high level methylation and with transcriptional silencing.

\section{Glycolipid Transfer Activity of Human GLTP Homologs}

As pointed out earlier, comparison of human 5-exon/4intron GLTP with GLTPi revealed encoding of all amino acid residues known to be important components of the glycolipid liganding site, including the glycolipid recognition center (Asp48, Asn52, Lys55, Trp96, His140, Tyr207, Val209) and the hydrophobic tunnel (Leu4, Leu30, Phe33, Phe34, Leu37, Val41, Phe42, Pro44, Ile45, Ile49, Phe103, Ile104, Phe107, Leu108, Ala128, Leu136, His140, Val144, Ile147, Ala151, Leu152, Ala155, Phe161, Leu165) $[16,29]$. To directly test whether GLTPi could be a source of active protein in human cells, the two GLTP homologs were heterologously expressed in E. coli, purified from the soluble fractions, and analyzed for their ability to transfer glycolipid between phospholipid bilayer vesicles in vitro. Two findings were noteworthy. First, compared to 5-exon/4-intron GLTP, the solubility of the GLTPi paralog was very poor, as indicated by its high accumulation in the inclusion bodies of $E$. coli (Figure 5A), consistent with a tendency to misfold. Second, GLTPi
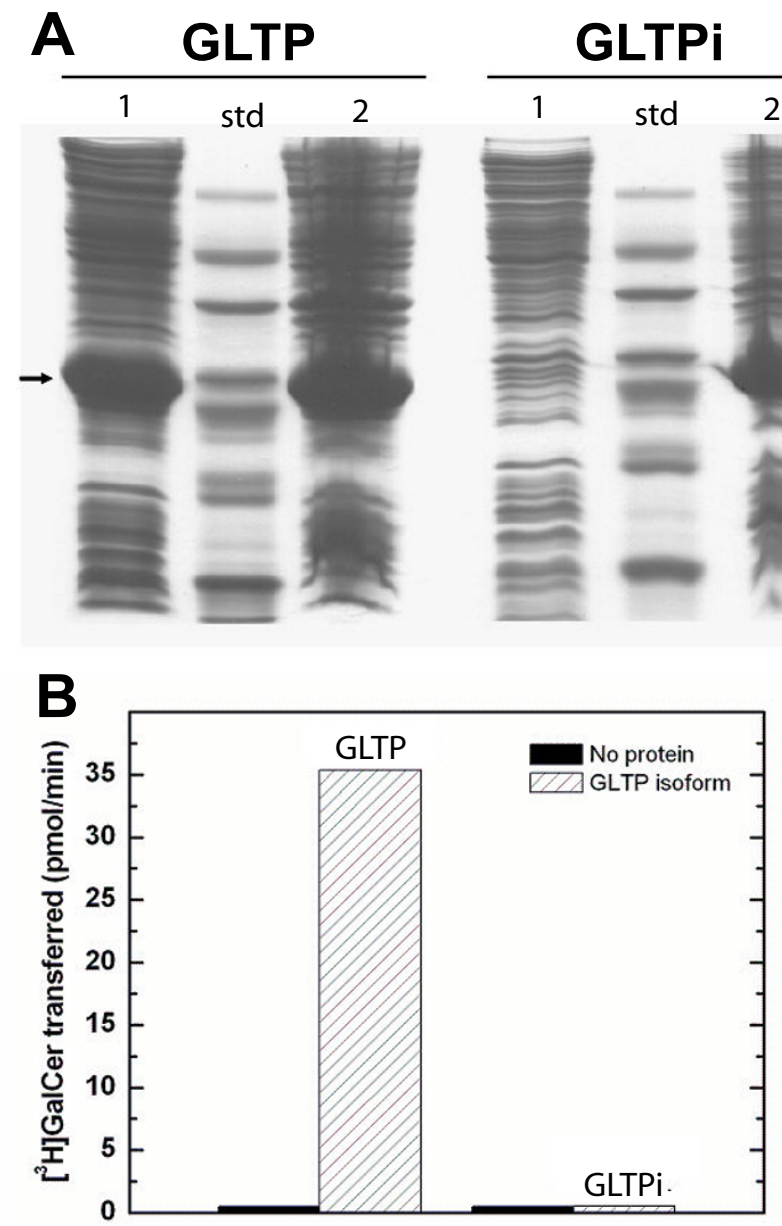

\section{Figure 5}

Heterologous Expression and Glycolipid Intermembrane Transfer Activity of Human GLTP Homologs. A. Heterologous expression of GLTP homologs in E. coli using PET-30 vector shown by SDS-PAGE. Arrow shows migration position of $6 \times$ His-S-GLTP homologs $(\sim 25 \mathrm{kDa})$. GLTP = left panel; Intronless GLTP $($ GLTPi $)=$ right panel; Lane I = soluble fraction; Lane 2 = Inclusion body pellet. Std $=$ molecular weight standards. B. Intermembrane glycolipid transfer activity of GLTP homologs. $\left[{ }^{3} \mathrm{H}\right] \mathrm{GalCer}$ transfer measured as described in Methods and Materials. The bars represent the averages of 6 assays performed using $1.0 \mu \mathrm{g}$ of GLTP homolog.

paralog purified from the soluble fraction showed negligible activity compared to purified 5-exon/4-intron GLTP (Figure 5B) when assessed for glycolipid intermembrane transfer using the well-established radiolabeled and fluorescence energy transfer assays $[27,29,36,37]$. Inclusion of Triton X-100 at low concentration during protein expression did result in slightly increased distribution of GLTPi paralog to E. coli soluble fractions. Nonetheless, the resulting GLTPi paralog (purified from the soluble fraction) remained inactive (data not shown). 
To determine whether a mammalian cellular environment is needed for expression of active GLTPi paralog, human embryonic kidney cells (HEK 293T) were transfected with FLAG-CMV vector containing the GLTPi and GLTP ORFs. Analysis of the resulting cell supernatant fractions revealed a 20-fold increase in glycolipid intermembrane transfer activity above endogenous background levels for cells transfected with GLTP, but no increase in glycolipid intermembrane transfer activity for cells transfected with GLTPi (data not shown).

\section{Evolutionary Insights}

Table 1 summarizes the structural patterns found in the multi-exon GLTP genes of various vertebrates. The 5-exon/ 4 -intron organizational pattern, characteristic of the human GLTP gene at locus 12q24.11, was absolutely conserved, as were the sizes of analogous exons (e.g. exon 1 always 103 bases; exon 2 always 59 bases, etc.) in representative therian mammals and other vertebrates. In contrast, the size of analogous introns varied considerably among the 5-exon/4-intron GLTP genes. Nonetheless, intron 1 was consistently much larger than the other three introns and was exceptionally large in primates $(\sim 21,000$ bases).

In certain cases, sequence data for GLTP genes was found to be either missing or of very low reliability. This situation was evident for the predicted GLTP gene of Pan troglodytes (GenBank XM_522526; Ensembl, ver. 46, August 2007; [38]), based on careful comparisons to the human and macaque genes. To rectify the issue, the problematic G-C rich region of the chimp GLTP gene (e.g. exon 1) was cloned and sequenced using genomic DNA from chimpanzee fibroblasts (GenBank EF520721) by including PCR enhancers known to facilitate cloning of GLTP mRNA $[27,36]$. The resulting sequence of exon 1 in the chimp GLTP gene was found to be identical to that of the human 5-exon/4-intron GLTP gene (see Additional file 1, Figure S3). Molecular cloning of the GLTP ORF using mRNA from chimp fibroblasts (GenBank EF688398) con- firmed the identical nature of the encoded chimp and human GLTPs (209 a.a.).

Alignment of the five GLTP exons comprising the primate mRNA ORFs revealed very high conservation of nucleotide sequence (see Additional file 1, Figures S3 and S4). The human and chimp ORFs were 99.5\% identical, i.e. $627 / 630$ bases, and the human and macaque ORFs were $97.5 \%$ identical, i.e. $614 / 630$ bases. All nucleotide differences were synonymous $[39,40]$, i.e. no altered codon translation and all three primate GLTPs were identical in amino acid sequence (see Additional file 1, Figure S5). In nonprimate mammals, the GLTP ORFs had more nonsynonymous base substitutions (see Additional file 1, Figure S4), resulting in increased amino acid variability (see Additional file 1, Figure S5). Even so, high amino acid sequence homology was encoded in the 5-exon/4-intron GLTP genes of nonprimate mammals with sequence identity being $99 \%$ for Canis, $98.6 \%$ for Bos, $94.3 \%$ for Mus, and $90.4 \%$ for Monodelphis as well as for other vertebrates (e.g., $74.2 \%$ for Xenopus, $80.4 \%$ and $72.2 \%$ for Danio) compared to human 5-exon/4-intron GLTP.

Phylogenetic analyses (Figure 6) indicated that all sequences produced exactly the same tree topology by three independent methods [neighbor-joining (NJ), maximum parsimony (MP) and minimum evolution (ME)] $[39,40]$. Most of the major internal branches were well supported (Figure 6). Overall, the phylogenetic/evolutionary relationships observed for the 5-exon/4-intron GLTP gene conformed to the widely-accepted phylogeny of vertebrates. The situation for GLTPi was much different. Orthologs of the human GLTPi gene were discovered only in nonhuman primates (chimpanzee, macaque) and were not present in carnivora (dog), cetartiodactyla (pig, cow), rodentia (mouse, rat) or didelphimorphia (opossum), suggesting recent evolutionary development. The 'intronless' nature of the ORF sequences was consistent with origination by retrotransposition of mRNA derived from an ancestral 5-exon/4-intron GLTP gene. The structural fea-

Table I: Orthologs of Human 5-exon/4-intron GLTP Gene in Different Vertebrates

\begin{tabular}{|c|c|c|c|c|c|c|c|c|c|c|}
\hline Organism (GenBank ID) & Exon I ORF & Intron I & Exon 2 & Intron 2 & Exon 3 & Intron 3 & Exon 4 & Intron 4 & Exon 5 ORF & Identity a \\
\hline Homo sapiens (NM 016433) & 103 & 21,530 & 59 & 1,023 & 134 & 1,756 & 151 & 2,881 & 183 & 100 \\
\hline Pan troglodytes (EF688398) & 103 & N.D.b & 59 & 1,023 & 134 & $\mathrm{I}, 754$ & 151 & N.D.b & 183 & 100 \\
\hline Macaca mulatta (XM $001089 \mid 45)$ & 103 & 21,127 & 59 & 1,032 & 134 & $\mathrm{I}, 773$ & 151 & 3,017 & 183 & 100 \\
\hline Canis familaris (XM 84930I) & 103 & $|4,62|$ & 59 & 996 & 134 & 2,697 & $15 \mid$ & 1,674 & 183 & 99 \\
\hline Sus scrofa (NM 213822) & 103 & N.D.b & 59 & N.D.b & 134 & N.D.b & 151 & N.D.b & 183 & 98 \\
\hline Bos taurus (NM 175799) & 103 & 14,693 & 59 & 957 & 134 & 2,776 & 151 & 2,233 & 183 & 98 \\
\hline Mus musculus (NM 019821) & 103 & 13,079 & 59 & 1,222 & 134 & 2,060 & 151 & 3,464 & 183 & 94 \\
\hline Rattus norvegicus (XM 213793) & 103 & 13,396 & 59 & 1,668 & 134 & 1,882 & 151 & 1,558 & 183 & 93 \\
\hline Monodelphis domestica (XM 00|364000.1) & 103 & 7,138 & 59 & 1,873 & 134 & 3,442 & $15 \mid$ & 408 & 183 & 89 \\
\hline Xenopus tropicalis (NM 001016039.2) & 103 & 21,680 & 59 & 373 & 134 & 201 & $15 \mid$ & 3,371 & 183 & 74 \\
\hline Danio rerio (Chromosome 5) (XM 681171) & 103 & 5,545 & 59 & 83 & 134 & 3,039 & $15 \mid$ & 809 & 183 & 79 \\
\hline Danio rerio (Chromosome 10) (XM 692094.1) & 103 & 1,808 & 59 & 1,772 & 134 & 2,216 & 151 & $|, 33|$ & 183 & 71 \\
\hline
\end{tabular}

aThe percent identity is compared to the human protein sequence. bNot yet determined. 


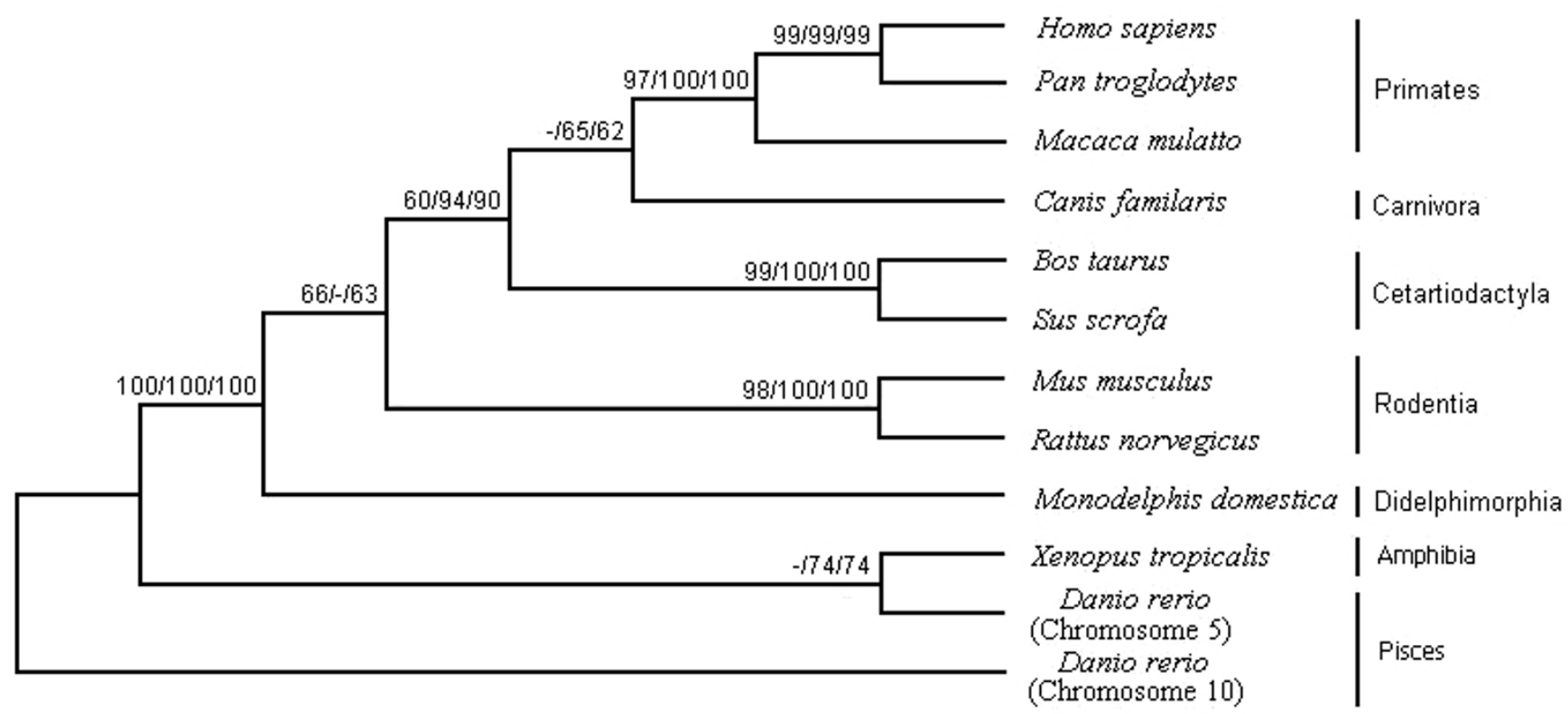

Figure 6

Phylogenetic Tree of 5-exon/4-intron GLTP Gene. Numbers correspond to percentages of bootstrap support for each node from the maximum parsimony, distance, and minimum evolution analyses. (Nucleotide and amino acid sequence alignments are provided as Additional file I, Figures S4 and S5).

tures supporting the common evolutionary ancestry of GLTPi genes in primates, included the following differences compared to their 5-exon/4-intron GLTP genes: 1) location on a different chromosome; 2) occurrence of nearly full-length GLTP ORFs ( 624 bases) including both start and stop codons; 3 ) absence of AGA at the same location in the sequence; 4) presence of the $\mathrm{CAG}^{435} \mathrm{ATC}$ TTC 441 sequence (after AGA deletion from the $\mathrm{CAG}^{435}$ AAGATC $\mathrm{TTC}^{444}$ region), keeping the potential reading frame fidelity intact and limiting downstream changes. The locations of the base changes within the affected GLTPi sequences are shown in Additional file 1, Figure S3. These shared and delineating features provided an unequivocal indication of the close evolutionary relationship among the GLTPi genes of primates.

Estimates of the evolutionary divergence for the 5-exon/4intron and GLTPi genes of primates and other primates provided insights into the selection pressure exerted on different phylogenetic branches. As shown in Table 2, base substitutions resulting in no change in amino acid residue (Ks) per synonymous site are compared with the nucleotide changes that do result in an amino acid alteration per nonsynonymous site $(K a)[41,42] . K_{\mathrm{a}} / K_{\mathrm{s}}$ ratios indicate the rate of evolution [42-44]. In Table 2, the higher $K_{\mathrm{a}} / K_{\mathrm{s}}$ ratios for 5-exon/4-intron GLTP genes among rodents compared to those among primates and cetartiodactylates are consistent with the rate of 5-exon/4-intron
GLTP protein evolution being faster in rodents than in primates and cetartiodactyla, after scaling to neutral divergence. Nonetheless, very low values for the $K_{\mathrm{a}} / K_{\mathrm{s}}$ ratios, i.e. zero and $<0.01$ for the exons of the 5-exon/4-intron GLTP genes in primates (Homo sapiens, Pan troglodytes, and Macaca mulatta) and cetartiodactyla (Bos Taurus and Sus scrofa) and of Mus musculus and Rattus norvegicus, are consistent with strong selection pressure to maintain and conserve the encoded amino acid sequence, as expected for genes playing important functional roles. In contrast, the GLTPi genes of Homo sapiens, Pan troglodytes, and Macaca mulatta show significantly higher $K_{\mathrm{a}} / K_{\mathrm{s}}$ values (Table 2 ), consistent with no evolutionary selection pressure being exerted on the primate GLTPi compared to their 5-exon/4intron GLTP genes, because $\mathrm{Ka} / \mathrm{Ks}$ values slightly below 1.0 are not de facto evidence of purifying selection pressure [45].

\section{Discussion}

GLTP has recently emerged as the prototypical and founding member of a new protein superfamily, characterized by a unique conformational fold for lipid binding/transfer as well as for protein targeting/translocation to membranes [13,17,19-22]. While recent advances have delineated the architecture used by GLTP to selectively acquire glycosphingolipid ligand [16-18] as well as the role played by membrane lipid composition in regulating GLTP activity in vitro $[13,37,46-50]$, the organization, 
Table 2: Synonymous $\left(K_{\mathrm{s}}\right)$ and nonsynonymous $\left(K_{\mathrm{a}}\right)$ nucleotide substitution rate for ORFs of vertebrate GLTP genes

\begin{tabular}{|c|c|c|c|c|c|}
\hline Species ${ }^{\mathrm{a}}$ & Substitutions & $b p^{b}$ & $K_{s}$ & $K_{\mathrm{a}}$ & $K_{\mathrm{a}} / K_{\mathrm{s}}$ \\
\hline \multicolumn{6}{|l|}{ GLTP } \\
\hline Hom/Pan & 3 & 627 & 0.01895 & 0.00000 & 0.00000 \\
\hline Hom/Mac & 17 & 627 & 0.10175 & 0.00000 & 0.00000 \\
\hline $\mathrm{Pan} / \mathrm{Mac}$ & 16 & 627 & 0.09212 & 0.00000 & 0.00000 \\
\hline Bos/Sus & 8 & 627 & $0.04|3|$ & 0.00000 & 0.00000 \\
\hline Rat/Mus & 33 & 627 & 0.22413 & 0.00196 & 0.00874 \\
\hline $\operatorname{Dan}(\operatorname{chr} 5) /(\operatorname{chrl0})^{c}$ & 194 & 627 & 1.99122 & 0.19415 & 0.09750 \\
\hline \multicolumn{6}{|l|}{ GLTPi } \\
\hline Hom/Pan & 12 & 624 & 0.02959 & 0.01556 & 0.52585 \\
\hline Hom/Mac & 44 & 624 & 0.08889 & 0.06576 & 0.73979 \\
\hline $\mathrm{Pan} / \mathrm{Mac}$ & 43 & 624 & 0.09884 & 0.05994 & 0.60643 \\
\hline
\end{tabular}

${ }^{\mathrm{a} G L T P}=$ functional 5-exon/4-intron GLTP gene and GLTPi = intronless GLTP gene. Hom, Pan, Mac, Bos, Sus, Mus, Rat and Dan indicate Homo sapiens, Pan troglodytes, Macaca mulatta, Bos taurus, Sus scrofa, Mus musculus, Rattus norvegicus and Danio rerio, respectively. bNumber of base pairs compared. cThe relatively high $K_{\mathrm{a}} / \mathrm{K}_{\mathrm{s}}$ ratio of 5 -exon/4-intron GLTP genes between Danio rerio GLTP genes on chromosome 5 and chromosome 10 suggests a functional change after duplication of one of the Danio rerio GLTP genes.

transcriptional status, phylogenetic/evolutionary relationships of human GLTP genes have not been previously characterized.

Our findings show the GLTP gene to be present in all vertebrate genomes and characterized by a highly conserved 5-exon/4-intron organizational pattern, consistent with mRNA production via classical cis processing events. The resulting GLTP transcript encodes a highly conserved mammalian protein able to selectively bind glycolipids and accelerate their intermembrane transfer [13]. The human 5-exon/4-intron GLTP gene maps to locus 12 q24.11 of chromosome 12 and is actively transcribed in variety of different cells, as shown by RT-PCR and by the unmethylated status of $\mathrm{CpG}$ dinucleotides in its $\mathrm{CpG}$ island. Noteworthy features of the 5-exon/4-intron GLTP gene are the very large size of its first intron $(>21,000$ bases) and the exceptionally high density of $\mathrm{CpG}$ dinucleotides (88) and of G-C bases ( $80 \%)$ in its CpG island. The very high $\mathrm{G}-\mathrm{C}$ content probably contributed to the poor sequence resolution evident in the GLTP gene of the recent Pan troglodytes (chimpanzee) genome release (GenBank NW 001223167; Sept. 2006), the resulting omission of exon 1 from the chimp GLTP gene (GenBank XM_522526), and inaccurate predictions of mRNA and protein sequence (Ensembl version 46, August 2007; [38]). Our cloning and sequencing of the genomic DNA of GLTP exon 1 as well as full-length GLTP ORF from mRNA of Pan troglodytes fibroblasts (GenBank EF520721 \&EF688398) have rectified the earlier inconsistencies and demonstrated the existence of the highly conserved 5exon/4-intron GLTP gene in chimpanzee.

The discovery of a second, intronless GLTP-like gene (GLTPi), encoding a full-length GLTP paralog in humans provided the opportunity to test for functionality as a ret- rogene. The issue is of timely relevance because of recent reports indicating transcription and regulatory functions of intronless pseudogenes [51-56]. Our analyses of GLTPi, which maps to locus 11p15.1 of chromosome 11, provide a clear indication of the challenges associated with definitive validation of pseudogene transcription. The experiments illustrate how PCR amplification involving closelyrelated sequences can detect even the slightest traces of genomic DNA contaminant in highly purified RNA isolates (see Additional file 1, Figure S1). It is clear that stringent controls are needed when using PCR to analyze the transcriptional status of intronless genes, including PCR controls performed in the absence of reverse transcriptase (No-RT controls), to avoid erroneous conclusions regarding the source of similarly sized templates (e.g. mRNA ORF versus genomic DNA of intronless gene). Such controls are needed even with DNase-treated mRNA isolates (see Additional file 1, Figure S1). In fact, it was possible to detect GLTPi genomic DNA in No-RT controls of mRNA isolates treated three times in succession with DNase, when the PCR thermal cycling number reached 42 or higher (data not shown). The PCR-associated caveats emphasize the need for independent analyses during evaluations of the transcriptional status of intronless genes that are highly homologous to the transcript of their parent genes. Reliance on the EST database as a complementary approach is risky because of documented evidence of substantial contamination from various sources including genomic DNA [57-59]. In contrast, a dependable complementary approach for monitoring gene transcriptional status is analysis of the methylation status of $\mathrm{CpG}$ islands commonly found in the 5'UTR of genes. The high methylation levels of the $23 \mathrm{CpG}$ dinucleotides in the CpG island of the intronless GLTP-like gene, along with the carefully controlled PCR data, provide strong evidence for this gene being a transcriptionally silent pseudogene. We find this 
to be the case despite the fact that GLTPi encodes an almost full-length ORF (627 vs 630 bases), complete with start and stop codons, and with an overall amino acid sequence homology of $94 \%$ compared to the active 5exon/4-intron GLTP. It is noteworthy that the 94\% homology is similar to that of human 5-exon/4-intron GLTP and mouse GLTP and much greater than that of the HET-C2 fungal ortholog [26] which actively transfers glycolipid. Also, heterologous expression of 5-exon/4-intron GLTP cDNA generated from human, bovine, porcine, and murine transcripts yields fully active protein in $E$. coli $[27,29,36,47-50]$, presumably because GLTP lacks intramolecular disulfides $[13,16]$ and needs no posttranslational modifications, i.e. glycosylation or acylation $[8,27]$. Nonetheless, the human GLTPi paralog is inactive and poorly soluble when expressed in E. coli. Ectopic expression in human embryonic kidney cells using FLAGCMV vector also resulted in inactive GLTPi. The absence of in vitro activity in the human GLTPi paralog occurs despite the fact that contains all residues previously identified as important components of the glycolipid liganding site, including the glycolipid recognition center (Asp48, Asn52, Lys55, Trp96, His140, Tyr207, Val209) and the hydrophobic tunnel (Leu4, Leu30, Phe33, Phe34, Leu37, Val41, Phe42, Pro44, Ile45, Ile49, Phe103, Ile104, Phe107, Leu108, Ala128, Leu136, His140, Val144, Ile147, Ala151, Leu152, Ala155, Phe161, Leu165) $[16,29]$. Our findings suggest that misfolding, triggered by one or more of the 13 altered residues, is responsible for the inactive state of human GLTPi. Identification of which of these GLTP residues or combination of residues are essential for proper folding will require future in-depth analyses.

Additional support for human GLTPi gene being a transcriptionally silent pseudogene comes from phylogenetic/ evolutionary divergence analyses that provide insights into the selection pressure being exerted on genes [41-44]. The frequencies of nonsynonymous (Ka) and synonymous (Ks) nucleotide substitutions for the GLTP functional and intronless genes (Table 2) are consistent with strong divergence of GLTPi relative to the 5-exon/4-intron GLTP genes. The relatively high $\mathrm{Ka} / \mathrm{Ks}$ ratios $(>0.5)$ for GLTPi of Homo sapiens, Pan troglodytes, and Macaca mulatta indicate that they have been subjected to very low evolutionary selection pressure. It is important to recognize that $\mathrm{Ka} / \mathrm{Ks}$ values slightly below 1.0 are not de facto evidence of significant purifying selection pressure. Indeed, a comprehensive genome-wide survey of human pseudogenes, performed against benchmark control sets of true genes and pseudogenes, revealed that only a small fraction $(\sim 12 \%)$ of pseudogenes have $\mathrm{Ka} / \mathrm{Ks}$ values very close to the theoretical neutral selection pressure value of 1.0 [45]. Rather, the majority of human pseudogenes have $\mathrm{Ka} / \mathrm{Ks}$ values very similar to those of the primate GLTPi pseudogenes. In contrast, the low $\mathrm{Ka} / \mathrm{Ks}$ ratios for the 5-exon/4-intron GTLP genes (e.g., 0 to $<0.01$ ) indicate strong purifying selection pressure to conserve the encoded amino acid sequence in order to maintain protein functionality.

\section{Conclusion}

The present study provides the first insights into the genomic organization, transcriptional status, and phylogenetic/evolutionary relationships of human GLTP genes, which encode the prototypical member of the recently established GLTP superfamily. The finding of a highly conserved 5-exon/4-intron GLTP gene in vertebrates vouches for the importance of GLTP in cells. Also noteworthy was the discovery of many errors in the on-line bioinformatics databases pertaining to GLTP genes, perpetuated by predictive modeling analyses that relied on low stringency survey data (e.g. exon deletion in the chimp GLTP gene) rather than on carefully executed experiments. The novel finding of a transcriptionallysilent, intronless GLTP gene in humans supports designation as GLTPP1, in accordance with guidelines for human gene nomenclature [60,61]. The discovery of GLTPP1 orthologs in other primates provides a new 'selection pressure free' marker for tracking primate evolutionary relationships. Clear delineation of the absence of transcription by human GLTPP1 was evident only by application of comprehensive and stringent experimental criteria, thus highlighting the challenges of unequivocally distinguishing silenced pseudogenes from functional retrogenes. In a larger context, the present study supports concerns about the validity of recent functional roles assigned to intronless pseudogenes. Among the most noteworthy is the recent re-evaluation of Mkrn1-p1 pseudogene 'functionality' [62], providing definitive evidence that the Mkrn1-p1 pseudogene is neither expressed nor imprinted, nor does it regulate its source gene in trans, despite earlier high profile indications to the contrary [54]. Equally important, the fundamental insights gained here into human GLTP gene organization, transcriptional status, and evolution provide a firm foundation for future elucidation and understanding of hereditary defects involving GLTP genes.

\section{Methods \\ Sequence Data}

Sequences determined as part of this study and deposited with the GenBank Data Library are: AF209704, $\underline{\mathrm{AY} 372530}, \underline{\mathrm{AY} 372531}, \underline{\mathrm{AY} 372532}, \underline{\mathrm{AF} 209703}, \underline{\mathrm{AY} 039109}$, EF520721, and EF688398

\section{Cell Culture and Genomic DNA Extraction}

All human cell lines were supplied by the American Type Culture Collection cell bank (ATCC, Rockville, MD). Human glioma cells, skin fibroblasts, HEK 293T cells, Gaucher cells, CaOV3 ovarian cancer cells, and breast can- 
cer cells (HBL100, T47D, HTB-126) were cultured at $37^{\circ} \mathrm{C}, 5 \% \mathrm{CO}_{2}$, in Dulbecco modified Eagle medium (DMEM) (Mediatech Inc, Herndon, VA) supplemented with $10 \%$ heat-inactivated fetal bovine serum (Innovative Research, MI). Human IMR32 neuroblastoma cells were cultured similarly but in DMEM supplemented with 10\% newborn calf serum (GIBCOBRL, Grand Island NY). Chimpanzee skin fibroblasts (Coriell Institute, Camden, NJ) were cultured at $37^{\circ} \mathrm{C}, 5 \% \mathrm{CO}_{2}$, in MEM Alpha Modified medium with nucleosides and L-glutamine (Fisher Sci., USA) supplemented with 10\% heat-inactivated fetal bovine serum (Innovative Research, MI).

\section{RT-PCR and DNA Sequencing}

Total RNA was isolated from cultured cells using Trizol reagent (GBICOL/BRL, Gaithersburg, MD, USA) according to the manufacturer's instructions, and was treated with DNase I (Sigma-Aldrich, St. Louis, MO) at $25^{\circ} \mathrm{C}$ for 15 min to minimize contamination by genomic DNA. SuperScript One-Step RT-PCR kits (Invitrogen, Carlsbad, CA) with Platinum Taq were used with RNA template (1 $\mu \mathrm{g})$. Human GLTP-specific primer pairs were 5'TGAAGCCGCTGCCCGCGGACA3' and 5'CGTAGATGA CATCGATGGTCG3'. RT-PCR reaction thermocycling conditions were: $30 \mathrm{~min}$ at $50^{\circ} \mathrm{C}, 2 \mathrm{~min}$ at $94^{\circ} \mathrm{C}$ or pre-cycle and then different cycles of $15 \mathrm{sec}$ at $94^{\circ} \mathrm{C}, 30 \mathrm{sec}$ at $63^{\circ} \mathrm{C}$, $1 \mathrm{~min}$ at $72^{\circ} \mathrm{C}$. $\beta$-actin served as internal RT-PCR control, performed in parallel with GLTP RT-PCR, using $\beta$-actin primer pairs of 5'GGCATCCTCACCCTGAAGTA3' and 5'CCATCTCTTGCTCGAAGTCC3' to produce a 496 base PCR fragment. With $\beta$-actin, PCR was limited to 30 cycles to avoid nonlinear responses. No-RT analysis also was performed as a control for detection of genomic DNA. PCR products were analyzed by $1.2 \%$ agarose gel electrophoresis, purified using a gel purification kit (NucleoTrap $^{\circledast}$ Gel Extraction Kit, Clontech, Mountain View, CA), and cloned using pGEM-T vector (Promega, Madison, WI, USA). Plasmids were digested by BspHI restriction enzyme, and the products were analyzed by agarose gel electrophoresis. Representative clones were sequenced by automated dideoxynucleotide sequencing using an ABI Prism 3730xl DNA analyzer (GENEWIZ, South Plainfield, NJ, USA).

\section{DNA Methylation Analysis}

Genomic DNA from human blood (Promega) or isolated from various cell lines (Sigma-Aldrich, GenElute ${ }^{\mathrm{TM}}$ mammalian genomic DNA miniprep kit) was bisulfite converted using manufacturer's recommendations (CpGenome Fast; Chemicon, Temecula, CA). Primers to amplify 5' regions of GLTP and intronless GLTP genes were (5'AATAGGAGAGTAGT-GTTTATTTAGGTTATT3' \& 5'ATCTTCCCCAAATATACCTCCC3') and (5'TTATTGTGATTATGA-AAATATATTAA-AAA3' \& 5'TAAACACTAAAAACCCAAAACAATC3'), respectively, using Platinum ${ }^{\circledR}$ Taq DNA Polymerase (Invitrogen, Carlsbad, CA). Cycling conditions for intronless GLTP were: step $1,94^{\circ} \mathrm{C}$ for $3 \mathrm{~min}$; step $2,94^{\circ} \mathrm{C}$ for 30 sec; step $3,50^{\circ} \mathrm{C}$ for $30 \mathrm{sec}$; step $4,72^{\circ} \mathrm{C}$ for $30 \mathrm{sec}$; step 5 , repeat 36 times; and step 6 , extend at $72^{\circ} \mathrm{C}$ for $10 \mathrm{~min}$. For GLTP, cycling conditions were the same except: step $2,90^{\circ} \mathrm{C}$ for $30 \mathrm{sec}$ and step $3,55^{\circ} \mathrm{C}$ for $30 \mathrm{sec}$. Amplified products were separated on $1.2 \%$ agarose gels, and the $255 \mathrm{bp}$ (intonless GLTP) and 201 bp (GLTP) bands were excised. The purified products from human blood genomic DNA were cloned directly into pGEM-T for DNA sequence analysis (Genewiz, South Plainfield, NJ).

COBRA analysis was performed as described previously [35]. The sodium bisulfite modified PCR products from different cell lines were reamplified for 38 PCR cycles using high-fidelity polymerase (Taq Plus, Stratagene, La Jolla, CA). PCR products $(15 \mu \mathrm{l})$ were restriction digested for $4 \mathrm{~h}$ at $60^{\circ} \mathrm{C}$ by addition of a master mix $(10 \mu \mathrm{l})$ equivalent to New England Biolabs Buffer \#2 (2.5 $\mu \mathrm{l})$, water $(5.5 \mu \mathrm{l})$ and BstUI $(2 \mu \mathrm{l}$ of 10 Units/ $\mu \mathrm{l}$; New England Biolabs). Restriction digests was analyzed by $1.2 \%$ agarose gel electrophoresis and ethidium bromide staining.

\section{Plasmid Construction and GLTP Expression}

GLTP and GLTPi ORFs were inserted into pET-30 Xa/LIC vector (Novagen) by ligation independent cloning [29]. Positive clones were verified for reading frame fidelity by nucleotide sequencing prior to transforming BL21(DE3) cells. For 6xHis-S-GLTP expression, bacterial cultures were grown at $37^{\circ} \mathrm{C}$ in Luria-Bertani medium $(750 \mathrm{ml})$ until reaching $\mathrm{OD}_{600}=0.9-1.1$. Cells were then induced by 0.1 $\mathrm{mM}$ isopropyl-beta-D-galactopyranoside and bacterial growth was continued at $15^{\circ} \mathrm{C}$ for $20 \mathrm{~h}$. The cell pellet was resuspended in washing buffer $(30 \mathrm{ml})$ containing $10 \mathrm{mM}$ imidazole, $150 \mathrm{mM} \mathrm{NaCl}, 50 \mathrm{mM} \mathrm{NaH}_{2} \mathrm{PO}_{4}, \mathrm{pH} 8.0,10 \%$ glycerol, $1 \mathrm{mg} / \mathrm{ml}$ lysozyme and $10 \mathrm{mM} \beta$-mercaptoethanol. After brief sonication and centrifugation, clarified cell lysate was loaded on 1-1.5 ml Ni-NTA affinity resin (Qiagen). The majority of protein was soluble. Protein was released from the washed column by stepwise elution with buffer containing increasing concentrations of imidazole $(60,100$ and $200 \mathrm{mM})$ in $150 \mathrm{mM} \mathrm{NaCl}, 50 \mathrm{mM}$ $\mathrm{NaH}_{2} \mathrm{PO}_{4}, \mathrm{pH}$ 8.0, and 5\% glycerol. Imidazole was removed from combined fractions by desalting columns (Econo-Pac 10 DG; Bio-Rad) equilibrated with $150 \mathrm{mM}$ $\mathrm{NaCl}$ and $50 \mathrm{mM} \mathrm{NaH} \mathrm{PO}_{4}, \mathrm{pH} 8.0$ and protein fractions were concentrated to $2-6 \mathrm{mg} / \mathrm{ml}$ using Centriplus centrifugical filter devices YM-10 (Amicon). Glycerol was added at $10 \%$ final concentration to stabilize and protect from freeze-thaw damage. Protein purity was analyzed by $15 \%$ SDS-PAGE and Coomassie staining. Protein concentration was measured by the Bradford assay (BioRad Protein Assay) using bovine serum albumin as standard. 6xHis-Stag was removed from rGLTP by incubation with Factor Xa 
(Novagen) for $16 \mathrm{~h}$ at room temperature to obtain a sequence identical to wild-type GLTP. The protein was purified by FPLC SEC using a HiLoad 16/60 Superdex-75 prep grade column (Amersham) equilibrated with 150 $\mathrm{mM} \mathrm{NaCl}, 20 \mathrm{mM}$ Tris ( $\mathrm{pH}$ 8.0). Protein fractions were concentrated to $2-6 \mathrm{mg} / \mathrm{ml}$ and stored in buffer containing $10 \%$ glycerol.

HEK 293T cells were plated at $1 \times 10^{5}$ densities, incubated until reaching 40-70\% confluency, and transfected with pFLAG-CMV ${ }^{\mathrm{rm}}-4$ vector $(2 \mu \mathrm{g})$ using jet PEI (Polypus Transfection, New York NY), a cationic polymer polyethylenimine (PEI) that forms complexes with DNA for efficient transfection of mammalian cells, after insertion of the wild-type human GLTP and GLTPi ORFs using the BamHI (5') and EcoRI (3') restriction sites and ligating with T4 ligase overnight at $16^{\circ} \mathrm{C}$. Control cells were transfected with pFLAG-CMV ${ }^{\mathrm{TM}}-4$ vector containing no GLTP cDNA insert. After $36 \mathrm{~h}$, transfected cells were selected based on resistance to G418 sulfate $(400 \mu \mathrm{g} / \mathrm{ml})$. Cells were harvested by scraping into buffer containing $20 \mathrm{mM}$ Tris, $50 \mathrm{mM}$ sucrose, $2 \mathrm{mM}$ EDTA, $2 \mathrm{mM}$ DTT, aprotinin, leupeptin, and PMSF. Homogenization was performed by 20 strokes with a Dounce homogenizer. The supernatant was recovered by centrifugation at $80 \mathrm{~g}$ for $10 \mathrm{~min}$ and assayed for glycolipid transfer activity.

\section{Assay of Glycolipid Transfer Protein Activity}

Glycolipid transfer activity was monitored as described previously [29,37]. Briefly, donor vesicles comprised of 89 mol\% 1-palmitoyl-2-oleoyl phosphatidylcholine (POPC), 1 mol\% [ $\left.{ }^{3} \mathrm{H}\right] \mathrm{GalCer}, 10 \mathrm{~mol} \%$ negatively charged dipalmitoyl phosphatidic acid and traces of $\left[{ }^{14} \mathrm{C}\right]$ tripalmitate (nonexchangeable marker) were prepared by sonication in $10 \mathrm{mM}$ sodium phosphate $(\mathrm{pH}$ 7.4), $1 \mathrm{mM}$ DTT, $1 \mathrm{mM}$ EDTA, and $0.02 \% \mathrm{NaN}_{3}$. Sonicated POPC vesicles served as acceptor membranes. After incubation with GLTP $(0.5-1 \mu \mathrm{g})$ for $30 \mathrm{~min}$ at $37^{\circ} \mathrm{C}$, charged donor and neutral acceptor vesicles were separated by rapid elution over DEAE Sephacel minicolumns and the glycolipid transfer activity of GLTP was determined by liquid scintillation counting of the eluants.

\section{Bioinformatics Analyses}

GLTP genes were identified by searches of NCBI databases [63] and ENSEMBL [38] against GLTP ORFs that we previously cloned from different mammalian cells $[16,27,36,47]$. BLAST searches of the nononredundant and EST databases [64] also were performed. K-Estimator 6.0, a divergence estimator program employing the Kimura two-parameter correction method for multiple hits, was used to estimate the frequency of synonymous and nonsynonymous nucleotide substitutions [41]. Phylogenetic analyses were carried out using three different methods, i.e. neighbor-joining (NJ), maximum parsi- mony (MP) and minimum evolution (ME), to construct distance trees with MEGA (Version 4.0) [39,40]. Bootstrap values were calculated from 1000 replicates and values of $<50 \%$ are not shown. CLUSTLX analysis [65] was used to comparatively align the open reading frames of the vertebrate GLTP genes.

\section{Abbreviations}

GLTP, glycolipid transfer protein; GSL, glycosphingolipid; EST, expressed sequence tag; RT-PCR, reverse transcription polymerase chain reaction; POPC, 1-palmitoyl-2-oleoysn-glycero-3-phosphocholine.

\section{Authors' contributions}

$\mathrm{XZ}$ and TC performed the RT-PCR transcriptional analyses. XZ performed the methylation and phylogenetic/evolutionary analyses. TC and XL cloned GLTP cDNAs from various cells and TC cloned the human GLTP pseudogene. MLM, TC and HMP expressed, purified, and analyzed the glycolipid transfer activity of the human GLTP paralogs. $\mathrm{XZ}, \mathrm{TC}$, and REB participated in the design and execution of the study. REB wrote and constructed the manuscript with contributions from XZ and TC. All authors read and approved the final manuscript. 


\section{Additional material}

\begin{abstract}
Additional file 1
Figure S1: RT-PCR/Restriction Analyses of Human GLTP and GLTPi cDNA in Various Human Cells. The strategy for distinguishing human GLTP and GLTPi cDNA clones by BspHI restriction analysis after RT$P C R$ is depicted. In 3xDNase-treated RNA isolates, GLTPi $c D N A$ clones occasionally are detected using 42 PCR cycles (panel B) but not when using 37 or fewer PCR cycles (panel C). The data suggest that genomic $D N A$ is virtually impossible to completely eliminate from RNA isolates. Independent assessment using No-RT PCR (e.g. Figure 3A, even numbered lanes) is required to clearly distinguish the source template ( $g D N A$ versus mRNA). Figure S2: CpG Islands in Human GLTP genes. The figure shows $C p G$ islands in human GLTP genes, identified using MethPrimer [34], and primer locations for COBRA analyses. The 5' untranslated region of human intronless GLTP gene (locus 11p15.1, chromosome 11) was found to be highly methylated (Figure 4), consistent with transcriptional silencing. Table S1: Number of synonymous substitutions per site $\left(\mathrm{K}_{\mathrm{s}}\right)$, non-synonymous substitutions per site $\left(\mathrm{K}_{a}\right)$ and confidence intervals. Divergence analyses based on estimates of the frequency of nonsynonymous $\left(\mathrm{K}_{a}\right)$ and synonymous $\left(\mathrm{K}_{s}\right)$ nucleotide substitutions between GLTP functional genes and intronless genes reveal that the intronless GLTP genes have diverged relative to 5-extron-4 intron GLTP. The data support information in Table 2 and suggest that the 5-extron-4intron GLTP genes have been subjected to strong selection pressure to conserve their amino acid sequences, characteristic of functional genes. The intronless GLTP genes are under much less selection pressure compared to the 5-extron-4-intron GLTP genes. Figure S3: GLTP and GLTPi Nucleotide Sequence Conservation in Primates. The data show the aligned nucleotide sequences and exon organizations for the GLTP genes and intronless GLTPi genes of humans, chimpanzees, and macaques. Figure S4: GLTP ORF Conservation in Vertebrates. The data show the aligned nucleotide sequences for the GLTP open reading frames found in various vertebrates from humans to fish. Figure S5: Conservation of GLTP Amino Acid Sequence in Vertebrates. The data show the aligned amino acid sequences for GLTPs that occur in various vertebrates from humans to fish.

Click here for file

[http://www.biomedcentral.com/content/supplementary/14712164-9-72-S1.pdf]
\end{abstract}

\section{Acknowledgements}

We thank Prof. Julian G. Molotkovsky (Russian Academy of Sciences) for synthesizing the fluorescent glycolipids used by Dr. Xiuhong Zhai to confirm the glycolipid intermembrane transfer activities of GLTP homologs obtained with radiolabeled glycolipids. We are grateful to Prof. Hervé Philippe (Université de Montréal) for recommendations regarding phylogenetics and evolutionary bioinformatics analyses, to Dr. Anthony J. Windebank (Mayo Clinic) for enabling access to the Mayo Molecular Biology Core Facility, and to Drs. Joshua Liao, Peter Ruvolo, and Vivian Ruvolo (UMNHormel Institute) for helpful suggestions. The research was supported by NIH/NIGMS GM45928, NIH/NCI CAI2 I493, and The Hormel Foundation. The authors have declared no conflict of interests regarding the findings, financing, and data reported herein.

\section{References}

I. Yamashita T, Wada R, Sasaki T, Deng C, Bierfreund U, Sandhoff K, Proia RL: A vital role for glycosphingolipid synthesis during development and differentiation. Proc Natl Acad Sci USA 1999, 96:9142-9147.
2. Bektas M, Spiegel S: Glycosphingolipids and cell death. Glycoconj J 2004, 20:39-47.

3. Schnaar RL: Glycolipid-mediated cell-cell recognition in inflammation and nerve regeneration. Arch Biochem Biophys 2004, 426: $163-172$

4. Viard M, Parolini I, Rawat SS, Fecchi K, Sargiacomo M, Puri A, Blumenthal $R$ : The role of glycosphingolipids in HIV signaling, entry and pathogenesis. Glycoconj J 2004, 20:2 I 3-222.

5. Gouaze-Andersson V, Cabot MC: Glycosphingolipids and drug resistance. Biochim Biophys Acta 2006, 1758:2096-2103.

6. Savage PB, Teyton $L$, Bendelac A: Glycolipids for natural killer $\mathbf{T}$ cells. Chem Soc Rev 2006, 35:77|-779.

7. Metz RJ, Radin NS: Purification and properties of a cerebroside transfer protein. J Biol Chem 1982, 257:I290I-I 2907.

8. Abe T, Sasaki T: Purification and some properties of the glycolipid transfer protein from pig brain. I Biol Chem 1985, 260: II23I-III239.

9. Brown RE, Stephenson FA, Markello T, Barenholz Y, Thompson TE: Properties of a specific glycolipid transfer protein from bovine brain. Chem Phys Lipids 1985, 38:79-93.

10. Gammon CM, Vaswani KK, Ledeen RW: Isolation of two glycolipid transfer proteins from bovine brain: reactivity towards gangliosides and neutral glycosphingolipids. Biochemistry 1987, 26:6239-6243.

II. Sasaki T: Glycolipid transfer protein and intracellular traffic of glucosylceramide. Experientia 1990, 46:6II-616.

12. Bankaitis VA, Cartee RT, Fry MR, Kagiwada S: Glycolipid transfer proteins. In Phospholipid Transfer Proteins: Emerging Roles in Vesicle Trafficking, Signal Transduction, and Metabolic Regulation Volume Chpt 5. New York: Springer; 1996:5I-72.

13. Brown RE, Mattjus P: Glycolipid transfer proteins. Biochim Biophys Acta 2007, 177 I:746-760.

14. Warnock DE, Lutz MS, Blackburn WA, Young WW Jr, Baenziger JU: Transport of newly synthesized glucosylceramide to the plasma membrane by a non-Golgi pathway. Proc Natl Acad Sci USA 1994, 91:2708-27I2.

15. Zegers MMP, Kok JW, Hoekstra D: Use of photoactivatable sphingolipid analogues to monitor lipid transport in mammalian cells. Biochem J 1997, 328:489-498.

16. Malinina L, Malakhova ML, Teplov A, Brown RE, Patel DJ: Structural basis for glycosphingolipid transfer specificity. Nature 2004, 430: 1048-1053.

17. Malinina L, Malakhova ML, Kanak AT, Lu M, Abagyan R, Brown RE, Patel $\mathrm{DJ}$ : The liganding mode of glycolipid transfer protein is controlled by glycosphingolipid structure. PLOS Biol 2006, 4:e362.

18. Airenne TT, Kidron H, Nymalm Y, Nylund M, West GP, Mattjus P, Salminen TA: Structural evidence for adaptive ligand binding of glycolipid transfer protein. J Mol Biol 2006, 355:224-236.

19. Murzin AG, Brenner SE, Hubbard T, Chothia C: SCOP: A structural classification of proteins database for the investigation of sequences and structures. J Mol Biol 1995, 247:536-540.

20. Structural Classification of Proteins (SCOP), Family: Glycolipid transfer protein (GLTP) [http://scop.mrc-lmb.cam.ac.ukl scop-1.69/data/scop.b.b.bja.b.b.A.html]

21. Madera M, Vogel C, Kummerfeld SK, Chothia C, Gough J: The SUPERFAMILY database in 2004: additions and improvements. Nucleic Acids Res 2004, 32:D235-D239.

22. Superfamily 1.69 , HMM library \& genone assignments server, Glycolipid transfer protein, GLTP superfamily [http:/ /supfam.org/SUPERFAMILY/cgi-bin/scop.cgi?sunid=1 10004]

23. Godi A, DiCampli AD, Konstantakopoulos A, Di Tullio G, Alessi DR, Kular GS, Daniele T, Marra P, Lucocq JM, De Matteis MA: FAPPs control Golgi-to-cell membrane traffic by binding ARF and Ptdlns(4)P. Nature Cell Biol 2004, 6:393-404.

24. D'Angelo G, Polishchuk E, Di Tullio G, Santoro M, Di Campli A, Godi A, West G, Bielawski J, Chuang C-C, van der Spoel AC, Platt FM, Hannun YA, Polishchuk R, Mattjus P, De Matteis MA: Glycosphingolipid synthesis requires FAPP2 transfer of glucosylceramide. Nature 2007, 449:62-67.

25. Brodersen P, Petersen M, Pike HM, Olszak B, Skov S, Odum N, Jorgensen LB, Brown RE, Mundy J: Knockout of Arabidopsis accelerated-cell-death II encoding a sphingosine transfer protein causes activation of programmed cell death and defense. Genes Dev 2002, 16:490-502. 
26. Mattjus P, Turcq B, Pike HM, Molotkovsky JG, Brown RE: Glycolipid intermembrane transfer is accelerated by HET-C2, a filamentous fungus gene product involved in the cell-cell incompatibility response. Biochemistry 2003, 42:535-542.

27. Li X-M, Malakhova ML, Lin X, Pike HM, Chung T, Molotkovsky JG Brown RE: Human glycolipid transfer protein: Probing conformation using fluorescence spectroscopy. Biochemistry 2004, 43:10285-10294.

28. Maniatis T, Tasic B: Alternative pre-mRNA splicing and proteome expansion in metazoans. Nature 2002, 418:236-243.

29. Malakhova ML, Malinina L, Pike HM, Kanack AT, Patel DJ, Brown RE: Point mutational analysis of the liganding site in human glycolipid transfer protein. Functionality of the complex. J Biol Chem 2005, 280:263।2-26320.

30. Wang PJ: $\mathbf{X}$ chromosomes, retrogenes, and their role in male reproduction. Trends Endocrinol Metab 2004, 15:79-83.

31. Gardiner-Garden M, Frommer M: CpG islands in vertebrate genomes. J Mol Biol 1987, 196:26I-282.

32. Jones PA, Baylin SB: The fundamental role of epigenetic events in cancer. Nature Rev Genet 2002, 3:4 I5-428.

33. Antequera F: Structure, function and evolution of CpG island promoters. Cell Mol Life Sci 2003, 60:1647-1658.

34. Li L-C, Dahiya R: MethPrimer: Designing primers for methylation PCRs. Bioinformatics 2002, I8:|427-|43।.

35. Xiong Z, Laird PW: COBRA: a sensitive and quantitative DNA methylation assay. Nucleic Acids Res 1997, 25:2532-2534.

36. Lin X, Mattjus P, Pike HM, Windebank AJ, Brown RE: Cloning and expression of glycolipid transfer protein from bovine and porcine brain. J Biol Chem 2000, 275:5 I04-5I I0.

37. Mattjus P, Pike HM, Molotkovsky JG, Brown RE: Charged membrane surfaces impede the protein-mediated transfer of glycosphingolipids between phospholipid bilayers. Biochemistry 2000, 39:1067-1075

38. Archive! Ensembl [http://aug2007.archive.ensembl.org/ index.html]

39. Baldauf SL: Phylogeny for the faint of heart: A tutorial. Trends Genetics 2003, 19:345-351.

40. Tamura K, Dudley J, Nei M, Kumar S: MEGA4: Molecular evolutionary genetics analysis (MEGA) software version 4.0. Mol Biol Evol 2007, 24:1596-1599.

4I. Li WH: Unbiased estimation of the rates of synonymous and nonsynonymous substitution. I Mol Evol 1993, 36:96-99.

42. Comeron JM: K-Estimator: calculation of the number of nucleotide substitutions per site and the confidence intervals. Bioinfomatics 1999, 15:763-764.

43. Hurst LD: The Ka/Ks ratio: diagnosing the form of sequence evolution. Trends Genetics 2002, 18:486-487.

44. Dorus S, Vallender EJ, Evans PD, Anderson JR, Gilbert SL, Mahowald M, Wyckoff G], Malcom CM, Lahn BT: Accelerated evolution of nervous system genes in the origin of Homo sapiens. Cell 2004, I 1 9: 1027-1040.

45. Torrents D, Suyama M, Zdobnov E, Bork P: A genome-wide survey of human pseudogenes. Genome Res 2003, 13:2559-2567.

46. Mattjus P, Klein A, Pike HM, Molotkovsky JG, Brown RE: Probing for preferential interactions among sphingolipids in bilayer vesicles using the glycolipid transfer protein. Biochemistry 2002, 41:266-273.

47. Rao CS, Lin X, Pike HM, Molotkovsky JG, Brown RE: Glycolipid transfer protein mediated transfer of glycosphingolipids between membranes: A model for action based on kinetic and thermodynamic analyses. Biochemistry 2004, 43: $13805-138 \mid 5$

48. Rao CS, Chung T, Pike HM, Brown RE: Glycolipid transfer protein interaction with bilayer vesicles: Modulation by changing lipid composition. Biophys J 2005, 89:4017-4028.

49. Nylund M, Mattjus P: Protein mediated glycolipid transfer is inhibited from sphingomyelin membranes but enhanced to sphingomyelin containing raft like membranes. Biochim Biophys Acta 2005, 1669:87-94.

50. Nylund M, Kjellberg MA, Molotkovsky JG, Byun HS, Bittman R, Mattjus $P$ : Molecular features of phospholipids that affect glycolipid transfer protein-mediated galactosyl-ceramide transfer between vesicles. Biochim Biophys Acta 2006, I 758:807-8I2.

51. Zhou BS, Beidler DR, Cheng YC: Identification of antisense RNA transcripts from a human DNA topoisomerase I pseudogene. Cancer Res 1992, 52:4280-4285.
52. Korneev SA, Park JH, O'Shea M: Neuronal expression of neural nitric oxide synthase (nNOS) protein is suppressed by an antisense RNA transcribed from an NOS pseudogene. J Neurosci 1999, 19:77| I-7720.

53. Balakirev ES, Ayala FJ: Pseudogenes: Are they 'junk' or functional DNA? Annu Rev Genetics 2003, 37:91-96.

54. Hirotsune S, Yoshida N, Chen A, Garrett L, Sugiyama F, Takahashi S, Yagami K, Wynshaw-Boris A, Yoshiki A: An expressed pseudogene regulates the messenger-RNA stability of its homologous coding gene. Nature 2003, 423:91-96.

55. Zheng D, Zhang Z, Harrison PM, Karro J, Carriero N, Gerstein M: Integrated pseudogene annotation for human chromosome 22: evidence for transcription. J Mol Biol 2005, 349:27-45.

56. Svensson Ö, Arvestad L, Lagergren J: Genome-wide survey for biologically functional pseudogenes. PLoS Comput Biol 2006, 2:e46.

57. Liang F, Holt I, Pertea G, Karamycheva S, Salzberg SL, Quackenbush J: Gene index analysis of the human genome estimates approximately I 20,000 genes. Nature Genetics 2000, 25:239-240.

58. Sorek R, Sager HM: A novel algorithm for computational identification of contaminated EST libraries. Nucleic Acids Res 2003 , 3I:1067-1074.

59. Hurteau G], Spivack SD: mRNA-specific reverse transcriptionpolymerase chain reaction from human tissue extracts. Anal Biochem 2002, 307:304-315.

60. Wain HM, Bruford EA, Lovering RC, Lush MJ, Wright MW, Povey S: Guidelines for human gene nomenclature. Genomics 2002, 79:464-470.

61. Guidelines for human gene nomenclature [http:// www.genenames.org/guidelines.html]

62. Gray TA, Wilson A, Fortin PJ, Nicholls RD: The putatively functional MkrnI-pl pseudogene is neither expressed nor imprinted, nor does it regulate its source gene in trans. Proc Natl Acad Sci USA 2006, 103:1 2039-12044.

63. NCBI BLAST assembled genomes [http://
] www.ncbi.nlm.nih.gov/BLAST/]

64. NCBI expressed sequence tags database [http:// www.ncbi.nlm.nih.gov/dbEST/index.html]

65. Thompson JD, Gibson TJ, Plewniak F, Jeanmougin F, Higgins DG: The ClustalX windows interface: flexible strategies for multiple sequence alignment aided by quantity analysis tools. Nucleic Acids Res 1997, 24:4876-4882.

Publish with Biomed Central and every scientist can read your work free of charge

"BioMed Central will be the most significant development for disseminating the results of biomedical research in our lifetime. "

Sir Paul Nurse, Cancer Research UK

Your research papers will be:

- available free of charge to the entire biomedical community

- peer reviewed and published immediately upon acceptance

- cited in PubMed and archived on PubMed Central

- yours - you keep the copyright 